\title{
Should I Stay or Should I Go? Understanding Teacher Motivation, Job Satisfaction, and Perceptions of Retention among Arizona Teachers
}

\author{
Craig A. Mertler ${ }^{1}$ \\ ${ }^{1}$ Division of Educational Leadership and Innovation, Arizona State University, Phoenix, USA \\ Correspondence: Craig A. Mertler, Division of Educational Leadership and Innovation, Arizona State University, \\ Phoenix, Arizona, USA.
}

Received: March 8, 2016

Accepted: March 22, 2016

Online Published: March 25, 2016

doi:10.5430/irhe.v1n2p34

URL: http://dx.doi.org/10.5430/irhe.v1n2p34

\begin{abstract}
This study attempted to describe the current status of teacher motivation, job satisfaction, and retention among teachers in the state of Arizona. All PK-12 public and charter school teachers in Arizona were asked to respond to a web-based survey, which included items about their overall job satisfaction, the motivational levels of various school-and non-school-based factors and performance incentives. Finally, they were asked a series of questions regarding their perceptions of teacher retention, including whether or not they had ever seriously considered leaving the profession and ratings of various conditions that would cause them to leave the profession, as well as those which would attract them to stay. Usable survey responses were received from 9,053 teachers. Results included an overall job dissatisfaction rate of $26 \%$, and several significant job satisfaction differences among demographic groups. Also presented are rankings of teacher ratings of the motivational levels for 18 job factors, 11 performance incentives, as well as reasons for leaving the teaching profession, and enticements for remaining in the profession. The discussion includes suggestions for the implementation of recognition-based programs for teachers in schools and districts.
\end{abstract}

Keywords: teacher motivation, job satisfaction, retention, self-perceptions

\section{Background}

Teacher motivation, job satisfaction, and teacher retention have been topics of research studies for decades. However, these remain important topics worthy of examination, as we continue to see shifts in the demands and expectations placed on our nation's teaching force. States and districts across the country are continually facing challenges associated with the hiring and retention of high quality teachers. In the last decade, we have observed the effects that national initiatives [such as No Child Left Behind (NCLB), Race to The Top (RTTT), and Common Core State Standards (CCSS), just to name a few], in addition to state initiatives (such as the implementation of new models of teacher evaluation) have had on our nation's teachers. The constantly increasing levels of accountability, as well as the increased levels of standardized testing, in our classrooms has arguably forced many teachers to change positions within the field of education or, more drastically, leave the profession altogether. A 2014 survey of 1,500 PK-12 teachers conducted by the National Education Association (NEA) revealed that while $75 \%$ of teachers were satisfied with their jobs, nearly half (45\%) indicated that had considered quitting the profession due simply to the increased emphasis on standardized testing (NEAToday, 2014).

\subsection{Job Satisfaction and Motivation among Teachers}

Over the years, many of the studies that have examined rates of teachers' job satisfaction have reported the percentages of those dissatisfied with their jobs to be roughly $20 \%-30 \%$. For example, a 1981 study conducted by the National Education Association (NEA) revealed a dissatisfaction rate of 25\% (Sweeney, 1981). Mertler (2001) reported a similar dissatisfaction rate of $23 \%$ of the teachers studied. The annual MetLife Teacher Survey (2011) reported a slightly lower overall dissatisfaction rate equal to $18 \%$. One of the highest rates of job dissatisfaction was reported by Perie and Baker (1997), at 32\%. Many of these studies also attempted to ascertain the percentage of teachers who, if provided with the opportunity to select a career over again, would not choose to enter the teaching profession. A sampling of these figures include findings of 34\% (Perie \& Baker, 1997), 36\% (Mertler, 2001), and 43\% (Brunetti, 2001). 
Research studies on this topic have also presented comparisons between demographic subgroups. These comparisons have offered some degree of conflicting results. For example, several studies have concluded that female teachers tend to report higher levels of job satisfaction than male teachers (King \& Peart, as cited in McConaghy, 1993; Ellis \& Bernhardt, 1992). Additionally, elementary teachers have reported higher satisfaction with their jobs than have secondary teachers (Perie \& Baker, 1997; King \& Peart, as cited in McConaghy, 1993; Ellis \& Bernhardt, 1992). Nevertheless, Mertler (2001) did not find significant differences based on gender or teaching level. In contrast, the only significant differences in teacher job satisfaction he found were based on age category and years of teaching experience. Generally speaking, early-career (and, typically, younger) teachers, as well as late-career (and, typically, older) teachers expressed greater levels of job satisfaction than did mid-career teachers.

Taken together, these findings suggest that motivation and satisfaction problems may exist in the teaching profession. Thus, teachers may be unmotivated in their teaching roles, as a result of the dissatisfaction with their chosen careers or due to the external stressors and accountability measures that have been placed on them (Mertler, 2001).

Fewer studies have specifically examined issues related to teacher motivation. In a national survey of 1000 inservice teachers, $67 \%$ responded that they knew teachers whom they believed to be incompetent and unmotivated, and that should be fired. When asked to specify the number of teachers who should be fired, the average response was three (Turner, 1986). In Mertler's (2001) study, secondary teachers were asked to rate the extent to which they believed that teachers, in general, are motivated, and to indicate the number of teachers with whom they worked that they would classify as unmotivated. Three-fourths (75\%) of all teachers surveyed indicated that they believe that teachers in general are motivated. When asked to indicate the number they believed to be unmotivated, the median response was 5-6 teachers. More specifically, $25 \%$ of teachers indicated that they knew 1-2 unmotivated teachers, $22 \%$ indicated 3-4 teachers, and another 15\% indicated 5-6 teachers. Very surprisingly, nearly another fourth (23\%) of the teachers surveyed indicated that they knew or worked with more than 10 teachers that they would classify as unmotivated.

\subsection{Context of Teaching in Arizona}

Since the research study at hand investigated teacher perceptions of job satisfaction, motivation, and retention among teachers in the state of Arizona, a brief description of the context of teaching in that particular state is warranted. In a 2015 ranking of the best and worst states for teachers in the U.S., Arizona received an overall ranking of $49^{\text {th }}$ out of 50 states and the District of Columbia, followed only by North Carolina and West Virginia (Bernado, 2015). These rankings were based on a formulaic combination of 13 metrics, including educational measures such as: average starting salary for teachers; median annual salary for teachers; teachers' income growth potential; projected number of teachers per 1,000 students by 2022; student-to-teacher ratio; safest schools; and public school spending per student.

According to the specific rankings, here is where Arizona fell on key measures: $49^{\text {th }}$ in annual salaries (adjusted for cost of living); $2^{\text {nd }}$ in the fewest number of teachers per student by $2022 ; 49^{\text {th }}$ in highest student-to-teacher ratio; $51^{\text {st }}$ in lowest public school spending per student; and $48^{\text {th }}$ in overall school systems ranking.

In a recent study of teachers living and working in southern Arizona, only $48 \%$ of teachers surveyed reported being satisfied with the career of teaching (Tucson Values Teachers, 2015). Further, this study reported on the sub-par salaries received by Arizona teachers when compared nationally to their peers. According to the report, the national median annual salary for secondary school teachers in 2014 was $\$ 56,310$. In Phoenix, the median figure was $\$ 9,000$ a year less $(\$ 47,230)$ and in Tucson, it was $\$ 18,000$ a year less $(\$ 38,240)$. The annual starting salary for an Arizona teacher is $\$ 31,874$ (Arizona Department of Education, 2015).

In his study of grades K-8 teacher satisfaction in an urban school district in Arizona, Halpert (2011) reported that 78\% of the teachers studied were satisfied with their jobs as teachers. Female teachers (90\%) indicated significantly higher levels of job satisfaction that did male teachers (45\%). Additionally, $90 \%$ of teachers at lower grades (i.e., K-4) stated that they were satisfied with their jobs, whereas only $23 \%$ of teachers of grades $5-6$ and $17 \%$ of teachers of grades $7-8$ indicated that they were satisfied. Finally, $36 \%$ of the participants in this study believed that a $10 \%$ increase in salary would be the most influential factor in terms of increasing their levels of job satisfaction.

One of the biggest issues facing Arizona when it comes to PK-12 education is retention of its teaching force. News media outlets are continually reporting on the teacher shortage and issues of retention across the state. Even national news outlets are reporting on the crisis. A recent story in the Washington Post (Strauss, 2015) stated:

"Teachers have been fleeing Arizona in droves, resulting in such a serious shortage of experienced teachers that state officials are warning of serious consequences if the exodus continues. Over the last five years, thousands of teachers 
have left the state, according to a 2015 report by the Arizona Department of Education, with this past school year being possibly the worst" (para. 1-2).

Reasons cited in the article for the mass exodus included low pay, insufficient classroom resources, and the multitude of testing requirements and teaching guidelines such that teachers feel they had no flexibility and too little authentic instructional time.

In a survey conducted by the Arizona School Administrators Association in November 2013, of the 79 districts who responded to the survey, $62 \%$ reported having open teaching positions within their schools, three months into the school year [as reported in Arizona Department of Education (ADE), 2015]. According to a 2014 ADE survey, 53\% of districts and charters reported that they had between one and five educators break their contract or resign midyear during the 2013-2014 school year (ADE, 2015). A 2013 study reported that nearly 30\% of the teachers surveyed did not think that they would be working in Southern Arizona classrooms five years from now, with $86 \%$ unlikely to recommend that others enter the education profession (Tucson Values Teachers, 2015). For several years, school district superintendents across the state have reported that approximately $30 \%$ of new teachers leave Arizona's school districts in their first three years, and 50\% leave within five years (Tirozzi, Carbonero \& Winters, 2014).

\section{Purpose of the Study}

Clearly, there exist serious and ongoing issues related to teacher satisfaction and retention in the state of Arizona. The purpose of this statewide survey research study was to better understand PK-12 teachers' self-reported perceptions of their teacher motivation, job satisfaction, and retention. From both short- and long-term perspectives, the results of this study could shed light on the types of incentives that motivate teachers to perform their responsibilities to the best of their abilities, but also to assist in retaining the best teachers across the state. There may also be implications for teacher preparation programs, in terms of establishing appropriate expectations and motivations among teachers new to the profession. Finally, although this study was limited to teachers in the state of Arizona, the ultimate findings would likely generalize - to some degree - to states across our country.

The research questions that guided the study were as follows:

1) What is the current status of Arizona teachers' satisfaction with their jobs as teachers?

2) How do teachers rate various aspects of the job of teaching in terms of the extent to which they serve as motivators or detractors?

3) How do teachers rate various intrinsic and extrinsic incentives in terms of their degree of motivation?

4) What are teachers' perceptions of their own retention in the teaching profession?

The results presented later in this paper have been organized by research question.

\section{Method}

\subsection{Participants}

All PK-12 public and charter school teachers in the state of Arizona during the 2015-2016 school year served as population of participants for this study. These participants were identified with the assistance of the communications and public relations staff at the Arizona Department of Education. All communications with the teachers were done electronically via school-based email addresses. The initial population consisted of 57,582 teachers. When the initial survey cover email was sent to these teachers, 6,582 "bounced back" due to email addresses that were incorrect or not current. This resulted in an actual population of $N=51,000$ teachers. Responses were received from 10,310 teachers; however, during processes of data screening, it was determined that 1,257 of these responses were incomplete - to varying degrees - and were deleted from the dataset. This resulted in a final sample size of $n=9,053$ completed and usable teacher surveys, representing a statewide response rate of $18 \%$. A detailed description of the characteristics of the sample is provided in the results section.

\subsection{Instrumentation}

The instrumentation used for data collection in this study was a self-developed survey, adapted from an earlier version of the same instrument (Mertler, 2001). The Teacher Motivation, Job Satisfaction, and Retention Survey is predominantly a forced-choice instrument, comprised of 59 content-based, forced-choice items, three open-ended items, and 10 demographic items. The content-based items were categorized under three sub-headings: job satisfaction, motivation, and perceptions of retention. The section on job satisfaction asked participants to respond to three forced-choice items: indications of their levels of satisfaction with their current position as a teacher, decisions 
relative to having opportunities to start over in a career and choosing to become teachers, and approximations of the numbers of teachers with whom they worked that they believed were satisfied with their jobs.

The majority of the items appearing in the section addressing motivation were originally adapted from the Motivator-Hygiene Theory developed by Frederick Herzberg (1966). Participants were asked to indicate, on a five-point Likert-type scale, the extent to which they believed that certain aspects of the job of teaching served as "motivating" or "unmotivating" factors for them. This section consisted of the 14 original job-related factors as outlined by Herzberg. In this study, however, the factor of "interpersonal relations" was divided into three distinct and separate factors (i.e., relationships with students, colleagues, and administrators). Additionally, two factors - namely, "teacher evaluation" and "accountability" - were added by the researcher, due to the fact that these are essential evaluation components associated with teaching. A portion of the section on motivation presented to participants 11 incentive items, loosely grouped as intrinsic and extrinsic motivators. Participants were again asked to indicate the extent to which these items served as "motivating" or "unmotivating" factors for teachers on the same five-point Likert-type scale.

Finally, the section on perceptions of teacher retention first asked participants the dichotomous question of whether or not each had ever seriously considered leaving the teaching profession. Participants were asked to indicate whether or not 14 specific aspects or situations of teaching would cause them to seriously consider leaving the profession, and then to respond to whether or not eight incentives would entice them to stay in their roles as teachers. These retention items were adapted from the Ohio Department of Education's Teacher Exit Survey (TExS) [Ohio Department of Education (ODE), 2011].

Analysis of the entire set of teacher responses $(n=9,053)$ resulted in an acceptable overall level of reliability of the instrument $(\alpha=.74)$.

\subsection{Procedures}

The electronic survey instrument was developed/revised from its previous version in late-summer, 2015. It was then transcribed and formatted in Qualtrics for ease of distribution and data collection. The Qualtrics version of the survey instrument went live on September 15, 2015. All data collection occurred over a six-week period during fall, 2015, specifically between September 15 and October 30. AZED distributed the cover email message, but with identifying information — such as the return email address, etc. — of the researcher, so as not to imply direct involvement with the survey or its specific contents on the part of AZED. The extent of AZED's involvement was simply the distribution of the study's email cover letter to its statewide database of public and charter school teachers. The cover letter was distributed in two phases, due largely to the fact that by September 15, a relatively high number of school districts had not yet updated their employee email lists with AZED. The first wave of emails was sent out on September 15 to 34,362 teacher email addresses. Of this number, 3,795 "bounced back," for various reasons, primarily that particular email addresses were no longer active. This resulted in a first-phase distribution equal to 30,567 teachers.

The second phase of email distributions went out on October 9. This email was originally sent to 23,220 teachers, of which there were 2,787 bounce backs. This resulted in a second-phase distribution equal to 20,433 teachers. Therefore, the entire cover email distribution was sent to and received by $N=51,000$ teachers. A brief email reminding the teachers of the October 30 due date for survey responses was sent to all 51,000 teachers on October 20. By October 30, a total of 10,310 responses to the survey had been received. However, upon examination of the data file itself, the researcher noted numerous incomplete sets of survey responses, at various points of the survey completion process. It was determined that any incomplete response set would be deleted from the final data analysis procedures. Therefore, 1,257 incomplete response sets were deleted from the database. Consequently, this resulted in a final, usable data set comprised of responses from $n=9,053$ Arizona teachers, representing an $18 \%$ statewide response rate.

Finally, it is important to note that an incentive for participation was offered to the teachers. Following completion of the actual survey, respondents were transported to a separate web site where they had the option to enter they names and email addresses in a random drawing for one of three \$50 VISA gift cards. This separate site ensured that their decision to be included in the drawing — along with the provision of their names and email addresses — was in no way connected to their substantive survey responses. A total of 7,907 responding teachers opted to be included in the random drawing for the gift cards. The random drawing was conducted using the "Select Cases... Random sample of cases" option within SPSS (v. 22). The drawing was conducted on November 10, 2015, and the winners were notified and sent their gift cards the following week. 
Data analyses were primarily descriptive, in nature. However, tests of independence between variables were conducted for the survey item asking respondents about their levels of satisfaction with the job of teaching and various demographic variables. Additionally, effect sizes were computed for these various tests of significance, using Cramér's $V$ statistic. According to Gravetter and Wallnau (2013), Cramér's $V$ is an appropriate test for effect size following a chi-square analysis when the cross-tabulation matrices are greater than $2 \times 2$ (which was the case for all significance tests performed, with the exception of the gender comparison; however, in this case, the effect size measured with Cramér's $V$ is identical to the value if measured using a phi-coefficient, $\varnothing$ ).

\section{Results}

All data were analyzed using the Statistical Package for the Social Sciences (SPSS), v. 22. The final sample $(n=$ $9,053)$ consisted primarily of female teachers $(78 \%)$. The ethnicity of the vast majority of responding teachers was Caucasian (81\%), followed by Hispanic (10\%). Thirty-nine percent held at least a Bachelors' degree (some with additional hours), while more than half (54\%) held Masters degrees (again, some with additional hours). Only $2 \%$ percent held terminal degrees. Eighty-seven percent of teachers reported teaching in public schools; $13 \%$ indicated that they taught in charter schools. Nearly half $(44 \%)$ of the teachers were currently working in elementary schools, followed by $31 \%$ in high schools, $17 \%$ in middle schools, and 3\% in PK-12 buildings. The majority (29\%) of teachers reported that their schools would be classified as suburban schools with moderate to high income, $20 \%$ indicated that they worked in urban schools with high poverty, $18 \%$ worked in rural schools with high poverty, $11 \%$ worked in urban schools with very high poverty, and $8 \%$ reported working in rural schools with low poverty.

Interestingly, the distribution of age categories for the responding teachers was fairly even, with the greatest percentage of respondents $(16 \%)$ falling in the category of 56 years or older, followed by those $41-45$ years old (14\%), 51-55 years old (14\%), 46-50 years old (13\%), 36-40 years old (12\%), 31-35 years old (12\%), 26-30 years old (11\%), and, finally, those 21-25 years old ( $8 \%$ ). The distribution of respondents across categories of teaching experience did not parallel the distribution across age categories. More than one-fourth (26\%) reported having 1-5 years of teaching experience. This was followed by 6-10 years of teaching experience (20\%), 11-15 years (18\%), $16-20$ years $(15 \%), 21-25$ years $(10 \%), 36-30$ years $(6 \%), 31-35$ years $(4 \%)$, and 36 years or more $(2 \%)$. Nearly two-thirds $(63 \%)$ of respondents indicated that they had been teaching in their current positions for 5 years or less, and a total of $81 \%$ reported less than 10 years in their current positions.

\subsection{Results for Research Question \#1}

What is the current status of Arizona teachers' satisfaction with their jobs as teachers?

More than one-fourth (26\%) of the teachers responding to the survey indicated that they were either dissatisfied or very dissatisfied with their current jobs as teachers. An additional 17\% indicated that they were neutral about their level of job satisfaction. Over half (58\%) reported that they were either satisfied or very satisfied with their jobs.

A significantly higher proportion of males (28\%) than females (25\%) were dissatisfied with their teaching positions, $\chi^{2}(1, N=8,853)=7.99, p=.018, V=0.03$. Similarly, significant differences were found for teachers' reported ethnicity and levels of job satisfaction, $\chi^{2}(10, N=8,815)=31.72, p<.001, V=0.04$. Significantly higher proportions of teachers whose ethnicity was reported as "Other" (29\%) and Caucasian (26\%) than those reporting as Hispanic (23\%), African-American (22\%), Native American (19\%), and Asian or Pacific Islander (13\%) were dissatisfied with teaching. Significant differences were also found between highest levels of education, $\chi^{2}(14, N=$ $8,861)=58.69, p<.001, V=0.06$, with those holding a Masters +15 hours $(30 \%)$, an EdD or PhD (29\%), a Bachelors +30 hours $(28 \%)$, or a Masters +30 hours $(27 \%)$ reporting higher levels of job dissatisfaction than those holding a Masters (26\%), a Bachelors + $15(25 \%)$, or a Bachelors $(20 \%)$.

Significantly greater levels of job dissatisfaction were reported by teachers at upper age category levels, $\chi^{2}(14, N=$ $8,852)=84.61, p<.001, V=0.07$. Teachers ages 46-50 (30\%), 51-55 (28\%), 41-45 (28\%), 36-40 (26\%), and those 56 and older (26\%) were significantly more dissatisfied that those ages 31-35 (23\%), 26-30 (21\%), and 21-25 (19\%). Generally speaking, a similar pattern was apparent for years of teaching experience, with those having more years of experience reporting greater job dissatisfaction, $\chi^{2}(14, N=8,863)=72.11, p<.001, V=0.06$. Teachers with 21-25 years of teaching experience (31\%), those with $16-20$ years (29\%), 11-15 years (28\%), and 26-30 years of experience (27\%) showed significantly greater job dissatisfaction than those with $31-35$ years $(25 \%), 6-10$ years $(24 \%)$, and 1-5 years $(21 \%)$. A summary of the significant chi-square test results appears in Table 1. 
Table 1. Summary of significant Chi-Square results for level of job satisfaction

\begin{tabular}{llccc}
\hline Dependent Variable & \multicolumn{1}{c}{$\begin{array}{c}\text { Independent } \\
\text { Variable }\end{array}$} & $\chi^{2}$ Statistic & $p$-Value & Effect Size \\
\hline \multirow{2}{*}{ Job Satisfaction } & Gender & 7.986 & $.018^{*}$ & 0.03 \\
& $\begin{array}{l}\text { Ethnicity } \\
\text { Highest Level of }\end{array}$ & 31.718 & $<.001 * *$ & 0.04 \\
& Education & 58.688 & $<.001 * *$ & 0.06 \\
& Age & 84.605 & $<.001 * *$ & 0.07 \\
& Years of Teaching & 72.109 & $<.001 * *$ & 0.06 \\
& Experience & 34.011 & $<.001 * *$ & 0.06 \\
& School Type & 67.744 & $<.001 * *$ & 0.06 \\
& School Setting & 16.556 & $.035^{*}$ & 0.03 \\
\hline
\end{tabular}

$* p<.05 . \quad * * p<.001$.

Teachers currently working in public schools reported significantly greater levels of dissatisfaction with teaching than did their charter school counterparts, $\chi^{2}(2, N=8,861)=34.01, p<.001, V=0.06$. Twenty-six percent of public school teachers said they were dissatisfied with teaching; whereas, $20 \%$ of charter school teachers reported being dissatisfied. Teachers in suburban schools with high to very high income (32\%), those in urban schools with very high poverty (31\%), and those in urban schools with high poverty $(27 \%)$ reported significantly higher levels of dissatisfaction than did teachers in rural schools with high poverty $(25 \%)$, those in suburban schools with moderate to high income $(23 \%)$, and those in rural schools with low poverty $(18 \%), \chi^{2}(12, N=8,847)=67.74, p<.001, V=$ 0.06 . Finally, middle school teachers $(27 \%)$ and elementary teachers $(26 \%)$ reported significantly greater dissatisfaction than did high school teachers (25\%) and teachers in PK-12 positions $(24 \%), \chi^{2}(8, N=8,860)=16.56$, $p=.035, V=0.03$.

It is important to acknowledge the fact that, although there were numerous statistically significant group differences, they represented small effect sizes, at best. This is likely due to the fact that the sample size was so large.

In the job satisfaction section of the survey, teachers were also asked to indicate their desire to become a teacher if they had the opportunity to start over in a new career. Less than one-third $(31 \%)$ of the total number of teachers responded in the affirmative ("Yes, definitely!"). Nearly one-fourth (24\%) selected the "No way!" option, and almost half $(45 \%)$ of the teachers said that they were "really not sure...". Finally, teachers were asked to indicate the approximate number of teachers with whom they currently worked that are satisfied with their jobs. Thirty-six percent said that "a majority are satisfied," $52 \%$ indicated that only "a few are satisfied," and $11 \%$ reported that they believed that "no teachers are satisfied" with their jobs.

\subsection{Results for Research Question \#2}

How do teachers rate various aspects of the job of teaching in terms of the extent to which they serve as motivators or detractors?

In the section of the survey addressing issues of teacher motivation, teachers were asked to rate 18 factors of the job of teaching in terms of the motivational level of each individual factor. They were asked to rate each factor on the following 5-point scale: 1 = highly unmotivating; 2 = somewhat unmotivating; $3=$ neither; $4=$ somewhat motivating; 5 = highly motivating. The results are presented in Table 2 and are rank ordered in terms of the percentages of teachers who indicated that the factor was either somewhat motivating or highly motivating.

The highest-rated job factor in terms of its motivation for teachers was "sense of achievement" (91.3\%), followed closely by "interpersonal relationships with students" (90.7\%), "recognition" (88.3\%), and "interpersonal relationships with colleagues" (84.2\%). The lowest rated job factors were "teacher evaluation" (45.1\%), "factors in personal life" (49.8\%), "status of the profession" (50.7\%), "sense of accountability" (51.0\%), and "district policies" $(51.4 \%)$. 
Table 2. Rank ordering of motivational level of teaching job factors, based on percentage of teachers

\begin{tabular}{|c|c|c|}
\hline Rank & Teaching Job Factor & Percentage of Teachers \\
\hline 1 & Sense of achievement & $91.3 \%$ \\
\hline 2 & Interpersonal relationships with students & $90.7 \%$ \\
\hline 3 & Recognition & $88.3 \%$ \\
\hline 4 & Interpersonal relationships with colleagues & $84.2 \%$ \\
\hline 5 & Responsibility & $78.1 \%$ \\
\hline 6 & Potential for professional growth & $76.0 \%$ \\
\hline 7 & Work itself & $72.9 \%$ \\
\hline 8 & Working conditions & $68.3 \%$ \\
\hline 9 & Job security & $68.1 \%$ \\
\hline 10 & Salary & $64.9 \%$ \\
\hline 11 & Interpersonal relationships with administrators & $60.5 \%$ \\
\hline 12 & Supervision & $58.5 \%$ \\
\hline 13 & Potential for advancement & $56.6 \%$ \\
\hline 14 & District policies & $51.4 \%$ \\
\hline 15 & Sense of accountability & $51.0 \%$ \\
\hline 16 & Status of the profession & $50.7 \%$ \\
\hline 17 & Factors in personal life & $49.8 \%$ \\
\hline 18 & Teacher evaluation & $45.1 \%$ \\
\hline
\end{tabular}

Note. Values reported indicate the percentage of teachers rating each factor as either somewhat motivating or highly motivating.

\subsection{Results for Research Question \#3}

How do teachers rate various intrinsic and extrinsic incentives in terms of their degree of motivation?

An additional aspect of the motivation section of the survey asked teachers to rate various incentives of the job of teaching. The respondents were presented with 11 incentives and were again asked to rate each incentive on the following 5-point scale: 1 = highly unmotivating; 2 = somewhat unmotivating; $3=$ neither; $4=$ somewhat motivating; 5 = highly motivating. The results are presented in Table 3 and are rank ordered in terms of the percentages of teachers who indicated that the incentive was either somewhat motivating or highly motivating.

By far, the two highest-rated incentives of teaching were "having students thank you for assisting in the understanding of a difficult concept" (96.6\%) and "observing vast improvements in your students' performance since the beginning of the year" (96.4\%). The lowest ranking incentives included "an instructional professional development workshop offered by the district (you pay)" (10.3\%), "being given the opportunity to participate in teacher projects (e.g., curriculum development)" (56.2\%), "early retirement/contract buy-out" (56.7\%), and "being selected as 'Teacher of the Year' in the district" (57.7\%). The middle of the rankings included incentives such as awards (both monetary and non-monetary) and various forms of professional development. 
Table 3. Rank ordering of motivational level of teaching incentives, based on percentage of teachers

\begin{tabular}{|c|c|c|}
\hline Rank & Teaching Job Factor & Percentage of Teachers \\
\hline 1 & $\begin{array}{l}\text { Having a student thank you for assisting in the } \\
\text { understanding of a difficult concept }\end{array}$ & $96.6 \%$ \\
\hline 2 & $\begin{array}{l}\text { Observing vast improvements in your students' } \\
\text { performance since the beginning of the year }\end{array}$ & $96.4 \%$ \\
\hline 3 & $\begin{array}{l}\text { Being permitted to purchase additional equipment, } \\
\text { technology, and/or supplies for your classroom }\end{array}$ & $82.8 \%$ \\
\hline 4 & One-time monetary award & $77.9 \%$ \\
\hline 5 & Being awarded a plaque by your students & $73.1 \%$ \\
\hline 6 & $\begin{array}{l}\text { Being supported to engage in your own professional } \\
\text { growth through the implementation of classroom-based } \\
\text { action research }\end{array}$ & $69.9 \%$ \\
\hline 7 & $\begin{array}{l}\text { An instructional professional development workshop } \\
\text { offered by the district (district pays) }\end{array}$ & $67.4 \%$ \\
\hline 8 & Being selected as "Teacher of the Year" in the district & $57.7 \%$ \\
\hline 9 & Early retirement/contract buy-out & $56.7 \%$ \\
\hline 10 & $\begin{array}{l}\text { Being given the opportunity to participate in teacher } \\
\text { projects (e.g., curriculum development) }\end{array}$ & $56.2 \%$ \\
\hline 11 & $\begin{array}{l}\text { An instructional professional development workshop } \\
\text { offered by the district (you pay) }\end{array}$ & $10.3 \%$ \\
\hline
\end{tabular}

Note. Values reported indicate the percentage of teachers rating each teaching incentive as either somewhat motivating or highly motivating.

\subsection{Results for Research Question \#4}

What are teachers' perceptions of their own retention in the teaching profession?

The final section of the survey asked respondents to self-report on various questions related to the issue of teacher retention. First, teachers were asked to indicate simply whether or not they had every seriously considered leaving the teaching profession. Nearly $69 \%$ of teachers responded that they had seriously considered leaving the profession.

Second, respondents were asked to indicate if any of 14 provided circumstances would serve as reasons for them to seriously consider leaving the teaching profession. The results are presented in Table 4 and are rank ordered in terms of the percentages of teachers who indicated that the particular circumstance would, in fact, serve as a reason for them to consider leaving teaching. Without a doubt, teachers indicated that the most influential reason to leave the teaching profession would be to "seek a more competitive salary" $(70.9 \%)$. This was followed-however, not closely - by pursuing a career change, both outside of (47.8\%) and within the field of education (42.7\%). "Lack of a supportive work environment" (41.4\%), "administrative leadership" (39.3\%), and "unethical treatment" (34.0\%) were also cited by at least one-third of the responding teachers. Less influential reasons included "inadequate mentoring" (11.0\%), "inadequate training necessary for a position" $(11.1 \%)$, and a "lack of shared leadership" $(14.2 \%)$.

Finally, teachers were asked to indicate which of a similar set of circumstances might serve to entice them to stay in the profession, should they ever seriously considering leaving. The results are presented in Table 5 and are rank ordered in terms of the percentages of teachers who indicated that the particular circumstance would entice them to stay in the profession. A "pay increase" was cited by a vast majority (85.2\%) of teachers as a major incentive to entice them to stay in the profession. A majority also indicted that they would be enticed by having "more time to plan or prepare" $(60.0 \%)$ and having "smaller classes" $(54.8 \%)$. 
Table 4. Rank ordering of reasons to leave the teaching profession, based on percentage of teachers

\begin{tabular}{clc}
\hline Rank & \multicolumn{1}{c}{ Teaching Job Factor } & Percentage of Teachers \\
\hline 1 & Seek a more competitive salary & $70.9 \%$ \\
2 & Career change (outside of education) & $47.8 \%$ \\
3 & Career change (within education) & $42.7 \%$ \\
5 & Lack of a supportive work environment & $41.4 \%$ \\
6 & Administrative leadership & $39.3 \%$ \\
7 & Unethical treatment & $34.0 \%$ \\
8 & School culture & $30.3 \%$ \\
9 & Lack of opportunities for advancement & Lack of autonomy \\
10 & Dissatisfied with current assignment & $24.0 \%$ \\
11 & Lack of desire/willingness to support various reform & $21.4 \%$ \\
12 & efforts & $20.6 \%$ \\
13 & Lack of shared leadership & $16.8 \%$ \\
14 & Inadequate training necessary for position & $14.2 \%$ \\
\hline
\end{tabular}

Note. Values reported indicate the percentage of teachers responding in the affirmative that a particular circumstance would serve as a reason for them to leave the teaching profession.

Table 5. Rank ordering of reasons to stay in the teaching profession, based on percentage of teachers

\begin{tabular}{clc}
\hline Rank & \multicolumn{1}{c}{ Teaching Job Factor } & Percentage of Teachers \\
\hline 1 & Pay increase & $85.2 \%$ \\
2 & More time to plan or prepare & $60.0 \%$ \\
3 & Smaller classes & $54.8 \%$ \\
4 & Greater opportunities for collaboration with colleagues & $32.3 \%$ \\
5 & Greater opportunities for advancement & $29.4 \%$ \\
6 & Change in leadership style & $25.9 \%$ \\
7 & Better facilities & $22.4 \%$ \\
8 & Different administrator & $21.6 \%$ \\
\hline
\end{tabular}

Note. Values reported indicate the percentage of teachers responding in the affirmative that a particular circumstance would entice them to stay in the teaching profession. 


\section{Discussion}

In many respects, the results of this study have generally paralleled similar studies of teacher motivation and job satisfaction conducted over recent years. The overall rate of teacher job dissatisfaction in this study (i.e., 26\%) is roughly similar to others previously cited in the literature [e.g., 23\% (Mertler, 2001); 25\% (Sweeney, 1981); 32\% (Perie \& Baker, 1997)]. Similarly, 24\% of teachers in the study at hand indicated that, if provided with the opportunity again, they would not choose a career as a teacher; another $45 \%$ indicated that they were not sure if they would or not. Although the $24 \%$ figure in this study is somewhat lower than in previous studies (e.g., Mertler, 2001; Brunetti, 2001; Perie \& Baker, 1997), the fact that an additional 45\% were "on the fence" is equally-if not more-concerning.

From this study, one might be inclined to conclude that the state of PK-12 education in Arizona is not as bad as other reports indicate. For example, taking into consideration where Arizona falls in various national rankings of educational effectiveness, per pupil expenditures, teacher salaries, and student-teacher ratios (just to name a few measures), there might be a tendency to have predicted that the rate of teacher job dissatisfaction would have been much higher than the reported $26 \%$, and perhaps that even higher percentages of teachers would be considering a departure from their chosen careers in education. However, this is not a time for complacency, nor is it appropriate to try to examine these findings through "rose-colored glasses," all while attempting to contextualize the results within what many Arizonans consider to be a dire situation for the state's system of education.

Consider for a moment that, if one was to extrapolate the $26 \%$ rate of job dissatisfaction from the teachers responding to the survey to all teachers across the state of Arizona, roughly 13,260 teachers would be dissatisfied with their jobs as teachers. That is an enormous number of teachers who are literally — and openly — not happy with the work that they are contractually obligated and dedicated to perform. In addition-and perhaps even more alarming - if we were to extrapolate the $69 \%$ of teachers (who indicated that they have seriously considered leaving the teaching profession) to all teachers across Arizona, we would discover that potentially more than 35,000 teachers have seriously considered a possible exodus from the profession. Granted, even though the large sample of 9,053 teachers in this study should be acknowledged, accompanied by the fact that it is most certainly not a perfect representation of the entire state's population of teachers, this remains an alarming and frightening number that must be addressed, and sooner rather than later.

From this study, it is apparent that Arizona teachers are motivated intrinsically, but also desire at least some degree of extrinsic rewards and/or recognition. Although Arizona ranks $49^{\text {th }}$ in the U.S. in terms of annual teacher salaries, it was somewhat surprising that the job factor of "salary" was not ranked high by the teachers in this study as a key motivator for the job of teaching. Its rank was actually $10^{\text {th }}$ (out of the 18 job factors), with nearly $65 \%$ indicating that it served as a motivating factor for them. Several of the substantially higher-ranking job factors-e.g., "sense of achievement," "interpersonal relationships with students," "recognition," "interpersonal relationships with colleagues," and "responsibility" - could all be considered to be intrinsic types of motivators. Additionally, the top three highest-rated teaching incentives-i.e., "having a student thank you for assisting in the understanding of a difficult concept," "observing vast improvements in your students' performance since the beginning of the year," and "being permitted to purchase additional equipment, technology, and/or supplies for your classroom"- -would also be considered to be intrinsic incentives, as each ultimately results in more effective instruction and improved student learning. Teachers everywhere - including those in Arizona, as evidenced by this study - are motivated intrinsically, by the joy they experience in helping their students learn, grow, and develop as children and young adults.

That being said, however, the highest ranking reason reported by teachers for potentially leaving the profession would be to "seek a more competitive salary." Additionally, the highest ranking reason or enticement to remain in the teaching profession would be to receive a "pay increase." This contradictory data presents a conundrum for our school district and state leaders. One possible explanation might be that the teachers responding to this survey did not need to cite reasons for staying in the profession that revolved around their work with children - that aspect of their work is already present, and is something with which they are very satisfied.

Taking all of this into consideration, it is quite likely that Arizona's teachers are satisfied with the work that they perform, but not with the recognition they receive. While extrinsic things like salaries and the like are not what motivate teachers to teach, they do serve as important parts of society and simply being able to live a comfortable - but, certainly not extravagant - lifestyle. It is also debatable whether a job factor such as "recognition" is more intrinsic or extrinsic, but the fact remains that, in recent years, teachers have been collective victims of "teacher bashing" and having their profession collectively "dragged trough the mud" by mainstream media, as well as on social media. Recognition of a job well done is certainly an outward and visible means of demonstrating 
support, of acknowledging contributions to our society, and of saying "thank-you." As I think many teachers will tell us, they do not need a great deal of recognition — or perhaps even a great deal of additional salary —in order to feel valued and appreciated with respect to the valuable and meaningful work they do each day.

From a research — as well as from a practical — perspective, this study has shed light on the seemingly never-ending problems facing our teaching force, specifically when it comes to satisfaction with their jobs as teachers and their desire to remain in the teaching profession. It is recommended that additional research be conducted in efforts to dig deeper into the reasons behind the fact that more than one-fourth of the more than 9,000 teachers responding to the survey in this study are dissatisfied with their jobs. It would be interesting — and highly informative - to potentially learn more about why this particular subset of Arizona's teaching population is so dissatisfied with the job of being teachers. While the "simple" solution to address the issues of low salaries, and perhaps even lower levels of recognition, consists of the argument to provide salary increases, knowledge of these facts could lead individual schools, school districts, or perhaps even the state of Arizona as a whole to development and implement programs that focus on ways to recognize teachers for the difficult, but intrinsically rewarding, work they do, day in and day out.

Teacher salaries in the state of Arizona should be increased, at least to some degree. I doubt that any teacher in this state - or anywhere in the country, for that matter - would turn down an offer for an increased salary. However, I would argue that, for many professional educators, it might not take a huge salary increase to positively impact their levels of job satisfaction. In many cases, I would predict that many teachers would envision a salary increase not simply as additional income, but perhaps more so as a means of receiving some sort of recognition, valuation, and confirmation of the work they perform.

On the other hand, I am unsure as to whether or not a little more money in one's pocket every couple of weeks will solve the problems we are observing. Individual schools and districts need to invest time - and perhaps a little money - to develop recognition-type programs for their teachers. I say "recognition-type" programs because I do not believe that recognition needs to exist in the form of awards or public acknowledgements. For example, teachers value important aspects of the job such as professional development opportunities, preparation time, and collegial collaboration. Specifically, the teachers in this study indicated with majority agreement that these things are important to them and serve as work incentives. Teachers see the inclusion of these types of workplace components as positive recognition associated with the job of being a professional educator. When these things are not present in their day-to-day activities, it is as if part of their profession has been taken away from them. As a specific example, the issue of the appropriateness of professional development is critical for teachers. One-size-fits-all professional development simply is not appropriate for the vast majority of educators in today's climate (Mertler, 2013). As evidenced by the data at hand, teachers were presented with three types of professional development "scenarios" as incentives for performance. The highest-rated item of the three-with $70 \%$ indicating that this would serve as an incentive for them-was the opportunity to engage in job-embedded, relevant, and ongoing professional development in the form of classroom-based action research. This ranked higher than both types of professional development workshops that teachers typically experience.

Across our country, competent teaching professionals are being lost to a variety of other career fields, and this situation has seen drastic ramifications in the state of Arizona. In addition, many teachers who have remained in the classroom have become less than enthusiastic and energetic toward the work they are charged to perform-whether it be due to low salaries or an unfulfilled need for recognition. Unfortunately, the individuals most effected by this crisis are the students of these teachers. These students are being deprived of the opportunity to learn from a reasonably high proportion of these teachers who have the potential to be competent and successful. We need to collectively find mechanisms for valuing and recognizing the vitally important work performed by teachers in schools throughout Arizona and our nation.

\section{References}

Arizona Department of Education (ADE). (2015, January). Educator retention and recruitment report. Retrieved from http://www.azed.gov/wp-content/uploads/2015/02/err-initial-report-final.pdf

Bernado, R. (2015). 2015's best and worst states for teachers. Retrieved from https://wallethub.com/edu/best-and-worst-states-for-teachers/7159/

Brunetti, G. J. (2001). Why do they teach? A study of job satisfaction among long-term high school teachers. Teacher Education Quarterly, 28(3), 49-74. 
Ellis, N. E., \& Bernhardt, R. G. (1992). Prescription for teacher satisfaction: Recognition and responsibility. The Clearing House, 65(3), 179-182. http://dx.doi.org/10.1080/00098655.1992.10114196

Gravetter, F. J., \& Wallnau, L. B. (2013). Statistics for the behavioral sciences ( $9^{\text {th }}$ ed.). Belmont, CA: Wadsworth.

Halpert, M. A. (2011). Factors affecting teacher satisfaction in an urban school district (Doctoral dissertation, Arizona State University). Retrieved from http://repository.asu.edu/attachments/56353/content/Halpert_asu_0010E_10314.pdf

Herzberg, F. (1966). Work and the nature of man. New York: New American Library.

McConaghy, T. (1993). A profile of the teaching profession in Canada. Phi Delta Kappan, 74(6), 502-503.

Mertler, C. A. (2001). Job satisfaction and perception of motivation among middle and high school teachers. American Secondary Education, 31(1), 43-53.

Mertler, C. A. (2013). Classroom-based action research: Revisiting the process as customizable and meaningful professional development for educators. Journal of Pedagogic Development, 3(3), 39-43. Retrieved from http://www.beds.ac.uk/jpd/volume-3-issue-3/classroom-based-action-research-revisiting-the-process-as-customi zable-and-meaningful-professional-development-for-educators

National Education Association (NEA). (2014, November). NEA survey: Nearly half of teachers consider leaving profession due to standardized testing. Retrieved from http://neatoday.org/2014/11/02/nea-survey-nearly-half-of-teachers-consider-leaving-profession-due-to-standardi zed-testing-2/

Ohio Department of Education (ODE). (2011). Teacher Exit Survey (TExS). Retrieved from http://education.ohio.gov/getattachment/Topics/Teaching/Educator-Equity/Teacher-Exit-Survey/Teacher_exit_s urvey_finalmay_2011.pdf.aspx

Perie, M., \& Baker, D. P. (1997). Job satisfaction among America's teachers: Effects of workplace conditions, background characteristics, and teacher compensation. Washington, D.C.: National Center for Education Statistics.

Strauss, V. (2015, June 19). Why teachers are leaving Arizona in droves. The Washington Post. Retrieved from https://www.washingtonpost.com/news/answer-sheet/wp/2015/06/19/why-teachers-are-fleeing-arizona-in-drove s/

Sweeney, J. (1981). Professional discretion and teacher satisfaction. The High School_Journal, 65(1), 1-6.

Tirozzi, G. N., Carbonero, P., \& Winters, M. (2014, April). Addressing a shortage of high quality teachers: An escalating dilemma for Arizona schools (Education Policy Paper, Grand Canyon University). Retrieved from http://www.gcu.edu/Documents/addressing\%20a\%20shortage\%20of $\% 20 \mathrm{high} \% 20$ quality $\% 20$ teachers.pdf

Tucson Values Teachers. (2015). The teacher workforce talking education - Executive summary. Retrieved from http://tucsonvaluesteachers.org/pdf/az-teach-survey-exec-booklet.pdf

Turner, R. (1986, September). Teachers speak out about their evaluations. Learning, 58-67. 